\title{
Chronic Exposure of Rats to Cognition Enhancing Drugs Produces a Neuroplastic Response Identical to that Obtained by Complex Environment Rearing
}

\author{
Keith J Murphy*,', Andrew G Foley', Alan W O'Connell' and Ciaran M Regan' \\ 'Department of Pharmacology, Applied Neurotherapeutics Research Group, Conway Institute, University College Dublin, Belfield, Dublin, Ireland
}

Recent data suggest that Alzheimer's patients who discontinue treatment with cholinesterase inhibitors have a significantly delayed cognitive decline as compared to patients receiving placebo. Such observations suggest cholinesterase inhibitors to provide a diseasemodifying effect as well as symptomatic relief and, moreover, that this benefit remains after drug withdrawal. Consistent with this suggestion, we now demonstrate that chronic administration of tacrine, nefiracetam, and deprenyl, drugs that augment cholinergic function, increases the basal frequency of dentate polysialylated neurons in a manner similar to the enhanced neuroplasticity achieved through complex environment rearing. While both drug-treated and complex environment reared animals continue to exhibit memoryassociated activation of hippocampal polysialylated neurons, the magnitude is significantly reduced suggesting that such interventions induce a more robust memory pathway that can acquire and consolidate new information more efficiently. This hypothesis is supported by our findings of improved learning behavior and enhanced resistance to cholinergic deficits seen following either intervention. Furthermore, the level of enhancement of basal neuroplastic status achieved by either drug or environmental intervention correlates directly with improved spatial learning ability. As a combination of both interventions failed to further increase basal polysialylated cell frequency, complex environment rearing and chronic drug regimens most likely enhanced cognitive performance by the same mechanism(s). These findings suggest that improved memory-associated synaptic plasticity may be the fundamental mechanism underlying the disease modifying action of drugs such as cholinesterase inhibitors. Moreover, the molecular and cellular events underpinning neuroplastic responses are identified as novel targets in the search for interventive drug strategies for the treatment of neurodegenerative and neuropsychiatric disorders.

Neuropsychopharmacology (2006) 31, 90- 100. doi:I0.1038/sj.npp. I 300810; published online 29 June 2005

Keywords: nefiracetam; tacrine; deprenyl; phenytoin; NNC-7I I; NCAM polysialylation

\section{INTRODUCTION}

Many different approaches have suggested promise in the treatment of Alzheimer's disease, but only therapies designed to boost central cholinergic transmission have advanced to clinical use. Clinical trials examining cholinergic augmentation with acetylcholinesterase inhibitors (AChEIs), such as tacrine, rivastigmine, donepezil, and galantamine, have consistently detected symptomatic improvement of cognitive impairment in Alzheimer's disease (Irizarry and Hyman, 2001). Symptomatic improvement in these studies was modest. Relative to placebo, following 6 months of treatment, patients improved by $2.8-6.0$ points

*Correspondence: Dr KJ Murphy, Department of Pharmacology, Applied Neurotherapeutics Research Group, Conway Institute, University College Dublin, Belfield, Dublin 4, Ireland, Tel: +353 । 7|66778, Fax: + 353 | 7166920, E-mail: keith.murphy@ucd.ie

Received 22 July 2004; revised 8 April 2005; accepted 2 May 2005 Online publication: I June 2005 at http://www.acnp.org/citations/ Npp060105040333/default.pdf on the 70 point Cognitive Subscale of the Alzheimer's Disease Assessment Scale (ADAS-Cog; Knapp et al, 1994; Rogers et al, 1998; Rosler et al, 1999; Raskind et al, 2000; Burns et al, 2004).

Due to the unfavorable side effect profile of AChEIs, other drug classes, with distinctly different primary mechanisms of action, have been investigated and shown promise in the treatment of cognitive deficits associated with Alzheimer's disease. Moreover, several such potential Alzheimer's treatments have been shown to augment cholinergic function. For example, the nootropic antidementia agent nefiracetam stimulates nicotinic receptors as efficiently as galantamine and donepezil, an effect that is dependent on Gs protein(s) (Nishizaki et al, 2000; Shorvon, 2001; Narahashi et al, 2004). Also, the procognitive action of the monoamine oxidase B inhibitor, l-deprenyl, in aged rats and Alzheimer's patients is thought to result from monoaminergic-driven enhancement of cholinergic function, in particular, in the hippocampus (Tariot et al, 1987; Piccinin et al, 1990; Mangoni et al, 1991; Molinengo and Ghi, 1997). 
Thus, interventions with distinct primary targets may ultimately influence a common cholinergic pathway to mediate symptomatic relief.

Recent data suggest that patients who discontinue treatment with cholinesterase inhibitors have a significantly delayed cognitive decline as compared to patients receiving placebo (Farlow et al, 2000). Such observations suggest AChEIs to provide a disease-modifying effect as well as symptomatic relief and, moreover, that this benefit remains after drug withdrawal. Furthermore, it remains unclear if such drug-derived benefit is mechanistically similar to the protective action of environmental factors such as higher educational attainment known to correlate with reduced risk of Alzheimer- and Parkinson-related dementia (Snowdon et al, 1996; Glatt et al, 1996). It is not unreasonable to assume that both environmental and AChEI disease-modifying action(s) require persisting alteration in molecular mechanisms that underpin cognitive function in the medial temporal lobe, as these structures are particularly sensitive to degeneration in Alzheimer's disease (Terry et al, 1991; Dickson et al, 1995; Gomez-Isla et al, 1996; Krishnan et al, 2003). Associating molecular mechanisms with this drug-derived benefit provides an important step in the development of more effective therapeutic strategies for neurodegenerative conditions such as Alzheimer's disease.

Significant evidence exists to suggest that memory consolidation requires synaptic reorganization and, in particular, modulation of cell adhesion within the hippocampus (for reviews see Regan, 2004; Lamprecht and LeDoux, 2004). For example, the neural cell adhesion molecule (NCAM) is necessary for activity-dependent synaptic plasticity, such as that associated with hippocampal long-term potentiation (LTP) and avoidance conditioning and spatial learning paradigms (Doyle et al, 1992; Lüthi et al, 1994; Rønn et al, 1995; Alexinsky et al, 1997). Glycosylation of NCAM with extended chains of $\alpha 2,8$-linked polysialic acid (PSA) is also necessary for memory consolidation as their cleavage with endoneuraminidase prevents LTP and spatial learning (Becker et al, 1996; Muller et al, 1996; Kleene and Schachner, 2004). Within the hippocampus, a transient increase in polysialylation of neurons located at the dentate infragranular zone at $10-12 \mathrm{~h}$ following learning is necessary for memory consolidation (Fox et al, 1995; Murphy et al, 1996; Foley et al, 2003; Sandi et al, 2003). This neuroplastic mechanism is required for dendritic remodelling (Nothias et al, 1997; Hoyk et al, 2001) and is likely to be an important factor in the elaboration and integration of circuitry associated with the consolidation of novel behavioral repertoires (Wang et al, 2000).

Consistent with the existence of a common mechanism underlying an inherent disease-modifying action from augmentation of cholinergic function, we now demonstrate chronic administration of tacrine, nefiracetam, and deprenyl to increase the basal frequency of dentate polysialylated neurons in a manner similar to the enhanced neuroplasticity achieved through complex environment rearing. Moreover, reduced requirement for neuroplastic activation, improved maze learning, and increased resilience against cholinergic deficits accompany the enhanced NCAM PSA expression in the hippocampus following drug or environmental intervention.

\section{MATERIALS AND METHODS}

\section{Source of Animals}

Male Wistar rats were purpose bred and housed in the Biomedical Facility, University College Dublin. These were maintained in a $12 \mathrm{~h}$ light/dark cycle with ad libitum access to food and water.

\section{Effects of Chronic Drug Treatment or Complex Environment Rearing on Basal NCAM PSA Expression in the Hippocampal Dentate Gyrus}

Chronic drug treatment. For studies of drug action on basal NCAM PSA expression, postnatal day 40 animals were housed singly and assigned randomly to groups receiving nefiracetam, tacrine, deprenyl, phenytoin, NNC-711 (Figure 1$)$, or $0.9 \%(\mathrm{w} / \mathrm{v})$ saline vehicle in which all drugs were prepared. The doses employed for each drug and the animal numbers for this first phase are detailed in Table 1 . Where appropriate, these doses were chosen to reflect the clinical equivalent (McNamara, 2001; Standaert and Young, 2001). The animals were dosed daily via intraperitoneal injection from postnatal day 41 to postnatal day 80 . Just prior to drug administration, rat weight gain was monitored for possible adverse effects of treatment. Only the highest dose of tacrine exhibited a blunting of the growth curve, as might be expected from the hepatotoxicity associated with tacrine at this and higher doses (Blackard et al, 1998). However, no drug-induced abnormalities of open-field behavior were observed on any of the 3 days prior to the day of training (data not shown).<smiles>Nc1c2c(nc3ccccc13)CCCC2</smiles><smiles>Cc1cccc(C)c1NC(=O)N1CCCC1=O</smiles>

tacrine

nefiracetam<smiles>C#CCN(C)C(C)Cc1ccc(O)c(O)c1</smiles>
deprenyl<smiles>O=C1NC(=O)C(c2ccccc2)(c2ccccc2)N1</smiles>
phenytoin<smiles>O=C(O)C1=CCCN(CCON=C(c2ccccc2)c2ccccc2)C1</smiles>

NNC-711

Figure I Chemical structures of drugs used in study. 
Table I Chronic Drug Treatments Employed in Phase

\begin{tabular}{|c|c|c|}
\hline Drug class & Treatment & Dose \\
\hline Control & Saline & $0.9 \%(w / v)$ \\
\hline \multirow[t]{4}{*}{ Nöotropic } & Nefiracetam & $3.0 \mathrm{mg} / \mathrm{kg}$ \\
\hline & & $9.0 \mathrm{mg} / \mathrm{kg}$ \\
\hline & & $15.0 \mathrm{mg} / \mathrm{kg}$ \\
\hline & & $30.0 \mathrm{mg} / \mathrm{kg}$ \\
\hline \multirow[t]{3}{*}{ Cholinomimetic } & Tacrine & $1.0 \mathrm{mg} / \mathrm{kg}$ \\
\hline & & $3.0 \mathrm{mg} / \mathrm{kg}$ \\
\hline & & $6.0 \mathrm{mg} / \mathrm{kg}$ \\
\hline \multirow[t]{2}{*}{ MAO-B inhibitor } & Deprenyl & $5.0 \mathrm{mg} / \mathrm{kg}$ \\
\hline & & $10.0 \mathrm{mg} / \mathrm{kg}$ \\
\hline \multirow[t]{2}{*}{$\mathrm{Na}^{+}$channel blocker } & Phenytoin & $4.0 \mathrm{mg} / \mathrm{kg}$ \\
\hline & & $8.0 \mathrm{mg} / \mathrm{kg}$ \\
\hline GABAmimetic & NNC-7!I & $\mathrm{mg} / \mathrm{kg}$ \\
\hline
\end{tabular}

The $n$ number refers to initial studies characterizing the basal NCAM PSA expression only. Further animals were treated for studies on learning behavior, learning induced activation of NCAM polysialylation, and complex environment combination studies.

Complex environment rearing. Male Wistar rats were raised from weaning (postnatal day 25) to postnatal day 80 in complex environment or social groups. The complex environment consisted of a large purpose built $\left(1 \mathrm{~m}^{3}\right)$ stainless-steel cage in two sections connected by a ramp. The cage was filled with items designed to generate environmental stimulation, for example: wooden/plastic blocks, wood chips, plastic containers, tunnels, exercise wheels, balls, tubes, see-saws, water-pools, wheeled vehicles, alternative housing, hanging chimes, tight-ropes and bridges, rolling chimes, and mirrors. The composition and placement of these items was altered daily. In addition, extra walls and floors were inserted into the cage and the location of food and water sources changed daily. Animals were raised in this environment in groups of 30 . Social control animals were raised in groups of 15 under standard conditions that consisted of a runner cage $\left(100 \times 50 \times 30 \mathrm{~cm}^{3}\right)$ containing no enrichment but with $a d$ libitum access to food and water.

Immunohistochemistry. Upon killing, the whole brain was quickly dissected out, coated immediately in an optimal cutting temperature compound (Gurr, UK), snap-frozen in liquid nitrogen-cooled $n$-hexane, and stored at $-80^{\circ} \mathrm{C}$ until required for further processing. Horizontal sections of $12 \mu \mathrm{m}$ were cut from frozen brain tissue using a MICROM (Series 500) cryostat. Serial sections were obtained for analysis from a point $-5.6 \mathrm{~mm}$ from Bregma (Paxinos and Watson, 1986) and thaw-mounted onto $0.1 \%(\mathrm{w} / \mathrm{v})$ poly-1lysine coated glass slides. The brain sections were fixed in $70 \%(\mathrm{v} / \mathrm{v})$ ethanol for $30 \mathrm{~min}$, washed twice for $10 \mathrm{~min}$ in a washing buffer of $0.1 \mathrm{M}$ phosphate-buffered $0.9 \%$ saline, $\mathrm{pH}$ 7.4 (PBS), and incubated overnight $(20 \mathrm{~h})$ in a humidified chamber at room temperature with anti-PSA (generous gift of Professor G Rougon; Rougon et al, 1986). This primary antibody was diluted $1: 500$ in an incubation buffer composed of PBS containing $1 \% \mathrm{w} / \mathrm{v}$ bovine serum albumen (Sigma Chemical Co., UK) and $1 \% \mathrm{v} / \mathrm{v}$ normal goat serum (DAKO, Denmark) in order to eliminate nonspecific staining. The sections were washed again and exposed for $3 \mathrm{~h}$ to fluorescein-conjugated goat anti-mouse IgM (Calbiochem, UK) diluted $1: 100$ with incubation buffer. The sections received a final wash before being mounted in Citifluor ${ }^{\circledR}$ (Agar, UK), a fluorescence-enhancing medium.

The staining pattern was observed with a Leitz DM RB fluorescence microscope using an exciting wavelength of $495 \mathrm{~nm}$ and an emitting wavelength of $525 \mathrm{~nm}$. Immunofluorescence staining was specific as it was eliminated completely by omission of either the primary or secondary antibody and by preabsorbing anti-PSA with colominic acid $(1 \mathrm{mg} / \mathrm{ml}$; Sigma Chemical Co., UK), which contains $\alpha 2,8$ linked homopolymers of sialic acid (Murphy et al, 1996). Where relevant, sections were counterstained by a brief exposure (60 s) to propidium iodide ( $50 \mathrm{ng} / \mathrm{ml} \mathrm{PBS}$ ) that was detected using an excitation wavelength of $552 \mathrm{~nm}$ and an emission wavelength of $570 \mathrm{~nm}$. The total number of PSAimmunoreactive neurons in the dentate granule cell layer and at the hilar border were counted in seven alternate $12 \mu \mathrm{m}$ sections commencing $5.6 \mathrm{~mm}$ below Bregma, to preclude double counting of the $5-10 \mu \mathrm{m}$ perikarya. Cell counts were divided by the total area of the granule cell layer, which included all propidium iodide labelled cells, and multiplied by the average granule cell layer area, which was $0.15 \pm 0.01 \mathrm{~mm}^{2}$ at this level, and the mean calculated for each animal. These means were used to establish the mean \pm SEM for each animal group. Area measurements of propidium iodide stained granule cell perikarya were performed using a Quantimet 500 Image Analysis System. Parametric statistical comparisons were made using the Student's $t$-test and $p$-values $<0.05$ were taken to be significant.

\section{Effect of Chronic Drug Treatment or Complex Environment Rearing on Learning Ability and Memory-Associated Activation of NCAM PSA Expression}

For these learning experiments, a second cohort of animals were chronically exposed to tacrine, nefiracetam, and deprenyl, at doses of 1,15 , and $5 \mathrm{mg} / \mathrm{kg}$, respectively, or saline $(0.9 \% \mathrm{w} / \mathrm{v})$ from postnatal day 41 to 79 . These doses were selected as they produced the greatest increase in basal NCAM PSA expression in phase 1 . These animals were then divided into untrained naives $(n=3)$ and groups to be trained in either water maze $(n=5)$ or passive avoidance $(n=5)$ learning paradigms. Thus, as the animals were drugfree on day of training (postnatal day 80), no effects observed were attributable to acute drug action. In addition, social and complex environment groups raised together with the untrained animals analyzed in phase 1 were trained in either water maze $(n=5)$ or passive avoidance $(n=5)$. 
Passive avoidance training. On postnatal day 80 , animals were trained in a one-trial, step-through, light-dark passive avoidance paradigm (Fox et al, 1995). The smaller, illuminated compartment was separated from a larger compartment by a shutter that contained a small entrance. The floor of the training apparatus consisted of a grid of stainless-steel bars that could deliver a remotely controlled, scrambled shock $(0.75 \mathrm{~mA}$ every $0.5 \mathrm{~ms})$ for $5 \mathrm{~s}$ when the animal entered the dark chamber. At $12 \mathrm{~h}$ post-training, the animals were tested for recall of this inhibitory stimulus by placing them into the light compartment and noting their latency to enter the dark compartment. A criterion period of $600 \mathrm{~s}$ was used. Nonparametric statistical comparisons were made using the Mann-Whitney $U$-test and $p$-values $<0.05$ were considered to be significant. Animals were killed immediately following the $12 \mathrm{~h}$ recall test and their brains prepared and processed as above for immunohistochemical analysis of NCAM PSA expression.

Water maze training. On postnatal day 80 , animals were trained in the water maze. This spatial learning task has been described in detail previously (Murphy et al, 1996). Briefly, the water maze apparatus consisted of a large circular pool $(1 \mathrm{~m}$ diameter, $80 \mathrm{~cm}$ high, temperature $\left.26 \pm 1^{\circ} \mathrm{C}\right)$ with a platform $(11 \mathrm{~cm}$ diameter) submerged $1.5 \mathrm{~cm}$ below the water surface. Both the pool and the platform were constructed of black polyvinyl plastic and offered no intra-maze cues to guide escape behavior. The experimental room contained several extra-maze visual cues. During training the platform was hidden in the same quadrant $30 \mathrm{~cm}$ from the edge of the maze. Each of the five trials started with the rat facing the wall of the maze at one of three locations. The time taken by the rat to find the hidden platform within a $60 \mathrm{~s}$ period was recorded. On the first trial, rats failing to find the platform within the $60 \mathrm{~s}$ period were placed on it for $10 \mathrm{~s}$. Times to the platform were measured over five trials in the training session with an inter-trial interval of $300 \mathrm{~s}$. All data were calculated and graphed as mean \pm SEM and the presence of significant difference between conditions was determined by two-way ANOVA and post hoc Bonferroni analysis (GraphPad Prism
4 software). In all cases, values of $p<0.05$ were deemed to be significant. Animals were killed $12 \mathrm{~h}$ following the last trial and their brains prepared and processed as above for immunohistochemical analysis of NCAM PSA expression.

Correlation analysis. To seek a relationship between enhancement of basal hippocampal neuroplasticity and learning ability, these parameters were compared by Pearson correlation (GraphPad Prism 4 software; $p<0.05$ indicated significant correlation). Here, for each condition, the percent change in the basal NCAM PSA-positive cell number following the intervention (Table 2) was taken as an index of effect on neuroplasticity status while the mean latency to platform across all animals and all trials was taken as an index of spatial learning ability.

\section{Effect of Chronic Drug Treatment or Complex Environment Rearing on Amnesic Action of Acetylcholine Antagonism}

This study utilised the amnesic action of the acetylcholine antagonist scopolamine when administered $6 \mathrm{~h}$ postpassive avoidance training that we have previously described (Doyle and Regan, 1993). Briefly, animals were chronically exposed to nefiracetam $(15 \mathrm{mg} / \mathrm{kg} /$ day $)$ or saline $(0.9 \% \mathrm{w} / \mathrm{v})$ from postnatal day 41 to 79 or reared in social or complex environment as before. Again, as the animals were drug-free on day of training (postnatal day 80), no effects observed were attributable to acute drug action. On postnatal day 80 , all animals were trained in passive avoidance as above and administered scopolamine $(0.8-2.0 \mathrm{mg} / \mathrm{kg} ; 3 \leqslant n \leqslant 8) \quad 6 \mathrm{~h}$ after training. Each animal was tested for recall $24 \mathrm{~h}$ after training. An untreated control group was included to indicate normal avoidance recall latency. All data were calculated and graphed as mean \pm SEM escape latency and the presence of significant difference between conditions was determined by two-way ANOVA and post hoc Bonferroni analysis (GraphPad Prism 4 software). In all cases, values of $p<0.05$ were deemed to be significant.

Table 2 Effect of Chronic Administration of Nefiracetam, Tacrine, and Deprenyl or Complex Environment Rearing on Basal Expression and Learning-Induced Activation of NCAM PSA

\begin{tabular}{|c|c|c|c|c|c|c|}
\hline & \multicolumn{4}{|c|}{ Drug treatment } & \multicolumn{2}{|c|}{ Rearing } \\
\hline & Saline (\%) & Nefiracetam (\%) & Tacrine (\%) & Deprenyl (\%) & Social (\%) & Complex (\%) \\
\hline \multicolumn{7}{|l|}{ Naive } \\
\hline$\%$ increase over control & 0 & 28 & 18 & 16 & 0 & 33 \\
\hline \multicolumn{7}{|l|}{ Passive avoidance } \\
\hline$\%$ increase over basal & 39 & 9 & 16 & 2 & 57 & 20 \\
\hline
\end{tabular}




\section{Effect of Combining Chronic Drug Treatment and Complex Environment Rearing on NCAM PSA Expression}

Animals were raised in either social or complex environment groups as before. Within each environment animal groups received either nefiracetam $(15 \mathrm{mg} / \mathrm{kg} /$ day $)$ or saline $(0.9 \% \mathrm{w} / \mathrm{v})$ from postnatal day 25 to $79(n=4$ per treatment per environment). Animals were killed on postnatal day 80 and their brains prepared and processed as above for immunohistochemical analysis of NCAM PSA expression.

\section{RESULTS}

\section{Chronic Drug Treatment or Complex Environment Rearing Increase Basal NCAM PSA Expression in the Hippocampal Dentate Gyrus}

Chronic exposure to tacrine resulted in a significant increase in the frequency of polysialylated cells in the hippocampal dentate infragranular zone. This increase was observed with every dose employed, however, with the higher doses the polysialylated cell frequency tended to return to that observed in the saline control (Figure 2). This latter observation suggested a bell-shaped dose-response effect. Within the dentate gyrus, immunohistochemical procedures revealed the polysialylated cells to be located specifically at the infragranular zone with a well-established dendritic arbor extending through the granule cell zone and into the overlying molecular layer (Figure 3 ).

Nefiracetam, a well-established nöotrope (Shorvon, 2001) and the neuroprotective drug deprenyl (Ebadi et al, 2002) were employed to determine if increased dentate polysialylated cell frequency followed chronic administration of other agents that enhance acetylcholine and memory function. Nefiracetam exhibited an action very similar to that observed with tacrine. Increased polysialylated cell frequency was observed over a dose range of $9-30 \mathrm{mg} / \mathrm{kg}$ and the dose-response effect was bell-shaped (Figures 2 and 3). Furthermore, clinically relevant concentrations of

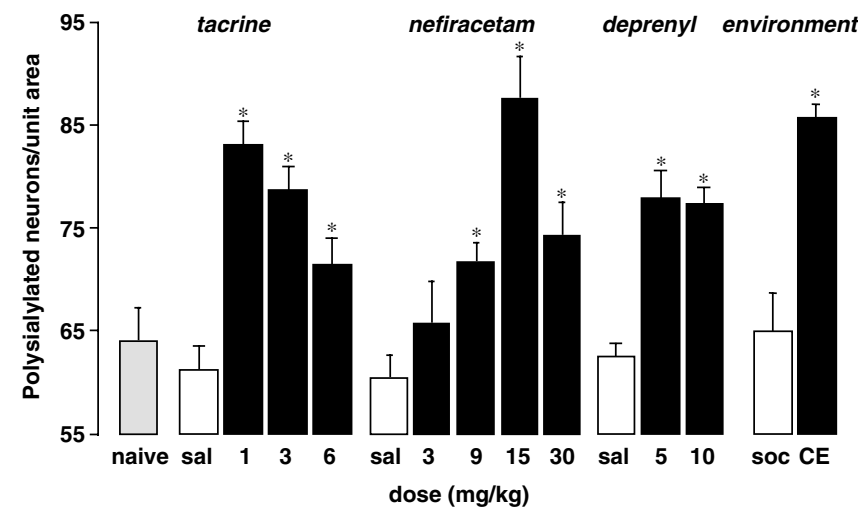

Figure 2 Influence of chronic treatment with nefiracetam, tacrine, deprenyl, or complex environment rearing on basal expression of polysialylated neurons in the hippocampal dentate infragranular zone. All data are the mean \pm SEM number of cells $/ 0.15 \mathrm{~mm}^{2}$ of the granule cell layer $(4 \leqslant n \leqslant 7)$. Values significantly different $(p<0.05$; Student's $t$-test) from naïve are indicated with an asterisk. sal: saline-treated $(0.9 \% \mathrm{w} / \mathrm{v})$; soc: social housing; CE: complex environment.
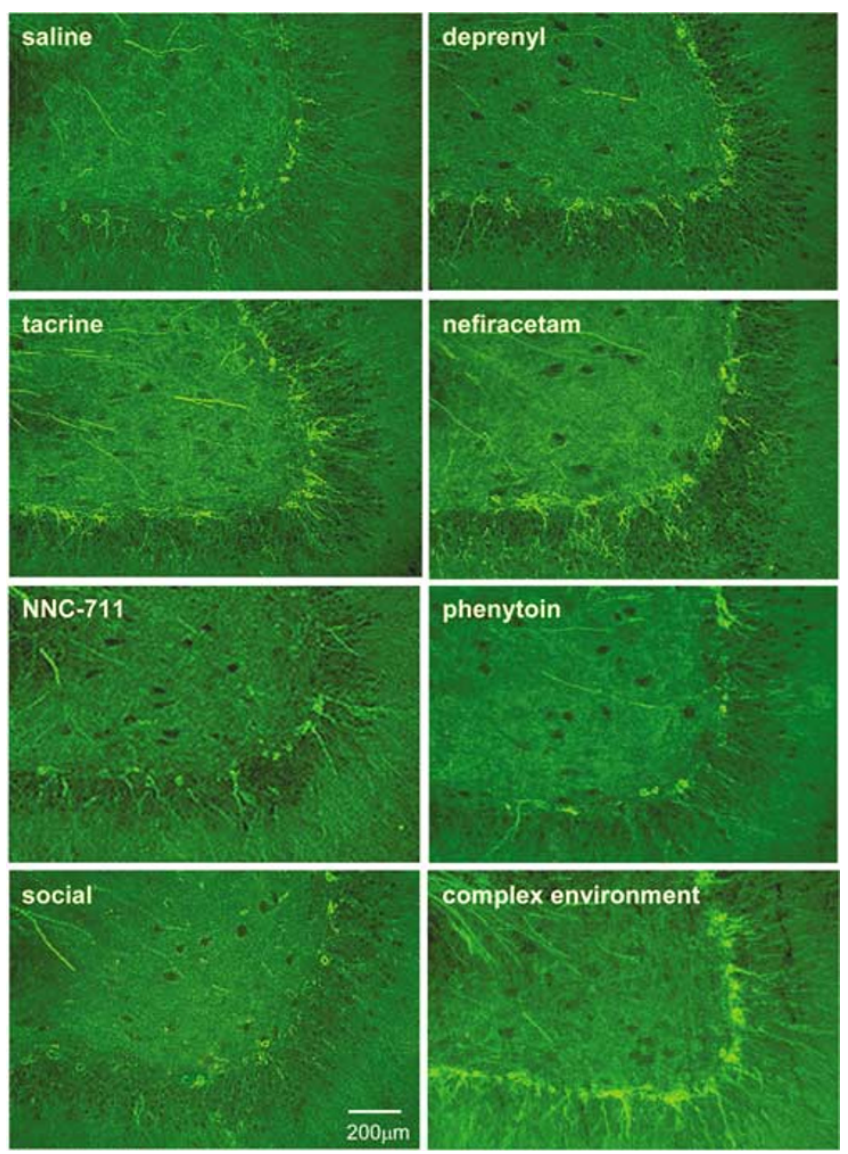

Figure 3 Photomicrographs illustrating the effect of chronic treatment with saline $(0.9 \% \mathrm{w} / \mathrm{v})$, deprenyl $(5 \mathrm{mg} / \mathrm{kg} /$ day $)$, tacrine $(\mathrm{lmg} / \mathrm{kg} /$ day $)$, nefiracetam ( $15 \mathrm{mg} / \mathrm{kg} /$ day), NNC-7| I (I mg/kg/day), phenytoin $(8 \mathrm{mg} / \mathrm{kg} /$ day) and rearing in a social or complex environment on the frequency of polysialylated hippocampal infragranular neurons in the postnatal day 80 male Wistar rat.

deprenyl (5 and $10 \mathrm{mg} / \mathrm{kg}$; Standaert and Young, 2001) when administered in a chronic manner resulted in a significant increase in dentate polysialylated cell frequency (Figures 2 and 3).

NNC-711, a GABA reuptake inhibitor and potent procognition agent that is not associated with enhanced cholinergic function, failed to increase basal polysialylated cell frequency (64.4 $\pm 3.9 v s$ 61.7 \pm 7.8 ; not significant) at $1 \mathrm{mg} / \mathrm{kg}$, the optimal dose of its bell-shaped cognition enhancing effect (O'Connell et al, 2001). Moreover, as may be expected, drugs without cognition-enhancing actions failed to increase polysialylated cell frequency following chronic administration. The anticonvulsant phenytoin was employed as it dampens neural activity through a sodium channel blocking mechanism and does not mediate cognition-enhancement (Rogawski and Porter, 1990; Kuo and Bean, 1994). At $4 \mathrm{mg} / \mathrm{kg}$, a dose in the mid-therapeutic range, or at $8 \mathrm{mg} / \mathrm{kg}$, a dosage approaching the upper limit of nontoxic levels (McNamara, 2001), chronic administration of phenytoin resulted in polysialylated cell counts of $64.3 \pm 2.2$ and $63.9 \pm 2.4$ cells/unit area, respectively, values not significantly different from those observed in vehicletreated animals $(62.8 \pm 1.5$ cells/unit area). Immunohistochemical procedures confirmed chronic administration of 
NNC-711 and phenytoin to be without effect on the integrity of the polysialylated neurons. In all cases, their location and extent of dendritic arbor reaching to the molecular layer remained unchanged (Figure 3 ).

As increased basal dentate polysialylated cell frequency has previously been observed following complex environment rearing (Young et al, 1999), we employed this paradigm to compare its effect with that obtained by chronic drug administration. Maintaining animals in this environment from postnatal day 25 to postnatal day 80 resulted in a significant increase in the frequency of polysialylated neurons at the dentate infragranular zone (Figures 2 and 3). Significantly, the increase in polysialylated cell frequency was indistinguishable from that observed following chronic treatment with the optimal doses either of tacrine, deprenyl, or nefiracetam.

\section{Chronic Drug Treatment or Complex Environment Rearing Improves Spatial Learning and Reduces the Extent of Neuroplastic Activation during Memory Consolidation}

Increased expression of basal polysialylated cell frequency may be suggestive of improved neuroplasticity. We evaluated this possibility by determining the magnitude of the learning-induced transient activation of NCAM PSA expression seen $12 \mathrm{~h}$ following training in both passive avoidance and water maze paradigms. Vehicle-treated animals exhibited learning-induced NCAM PSA activation following both tasks, the magnitude of which matched those observed previously (Fox et al, 1995; Murphy et al, 1996). Independent of task, animals receiving chronic nefiracetam, tacrine, or deprenyl exhibited no significant difference in the $12 \mathrm{~h}$ post-training frequency of NCAM PSA positive neurons as compared to the vehicle-treated control

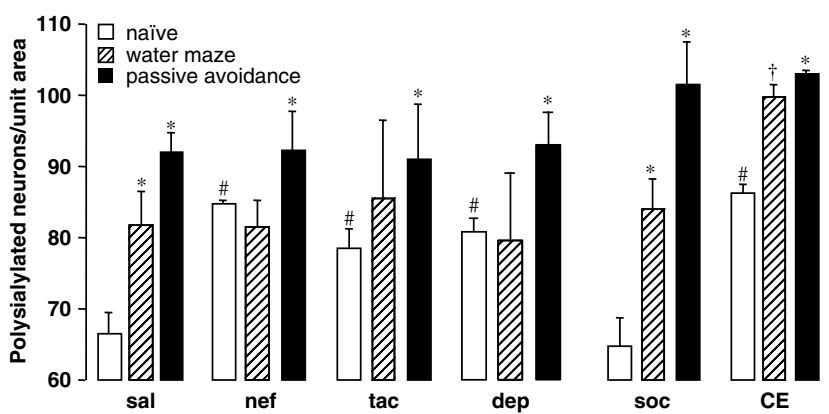

Figure 4 The influence of chronic treatment with tacrine $(\mathrm{l} \mathrm{mg} / \mathrm{kg} / \mathrm{day})$, nefiracetam ( $15 \mathrm{mg} / \mathrm{kg} / \mathrm{day}$ ), deprenyl ( $5 \mathrm{mg} / \mathrm{kg} / \mathrm{day}$ ), and complex environment rearing on the increase in NCAM PSA-positive neurons following water maze or passive avoidance training. The data are mean+SEM number of cells $/ 0.15 \mathrm{~mm}^{2}$ of the granule cell layer $(3 \leqslant n \leqslant 5)$, values significantly different $(p<0.05$; Student's $t$-test) from corresponding saline or social control are identified by a hash while trained values differing from the corresponding naïve animals are indicated by an asterisk. A cross indicates significant difference from both corresponding naïve animals and similarly trained, social control animals. sal: saline $(0.9 \% \mathrm{w} / \mathrm{v})$; nef: nefiracetam (I $5 \mathrm{mg} / \mathrm{kg} /$ day); tac: tacrine (I mg/kg/day); dep: deprenyl $(5 \mathrm{mg} / \mathrm{kg} /$ day); soc: social housing; CE: complex environment. NB: the last drug injection was administered $24 \mathrm{~h}$ prior to training to eliminate acute drug effects and animals reared in the complex environment were removed to social housing conditions $24 \mathrm{~h}$ prior to training.
(Figure 4). However, for either nefiracetam, tacrine, or deprenyl treatment, a significant frequency increase over respective basal level was observed only in the avoidance conditioning paradigm and, proportionally, this was much reduced compared to that seen in the vehicle-treated group (Figure 4 and Table 2). Thus, drug-induced increase of basal polysialylated cell frequency markedly reduced the PSA activation required during consolidation of water maze or avoidance conditioning. By contrast, complex environment rearing resulted in a significant increase in the $12 \mathrm{~h}$ frequency following both avoidance conditioning and spatial learning paradigms although for both tasks the magnitude was reduced compared to social control animals (Figure 4 and Table 2). The alteration in degree of neuroplastic activation, as measured by NCAM PSA expression change, is most instructively viewed as percent learning-associated change with respect to the corresponding basal expression (Table 2).

The drug and environmental protocols employed here may also have improved neural robustness as it pertains to learning capacity, as demonstrated previously for the complex environment paradigm (Young et al, 1999). We analyzed the spatial learning ability of the animals reared in a complex environment and those that had received chronic treatment with nefiracetam, tacrine, or deprenyl but, importantly, were $24 \mathrm{~h}$ drug-free at the time of training. While two-way, repeated measures ANOVA did not detect an effect of drug treatment across all groups, it did reveal improved learning in the complex environment reared group compared to social controls $(\mathrm{F}[3,16]=1.6, p=0.23$ and $F[1,8]=7.29, p=0.027$, respectively). However, both drug-treated and complex environment-reared animals exhibited significantly better performance across the five trials of the single water maze training session when compared with their corresponding controls (saline vs nefiracetam, tacrine, and deprenyl-treated, two-way ANOVA: $\mathrm{F}[1,40]=8.78, p=0.005 ; \mathrm{F}[1,40]=5.73, p=0.022$; and $\mathrm{F}[1,40]=5.78, p=0.026$, respectively; social $v$ s complex environment, two-way ANOVA: $\mathrm{F}[1,40]=19.08, p<0.0001$ ) (Figure 5). It is noteworthy that with both nefiracetam and environmental interventions, animals exhibited significantly better performance even on the first water maze trial when these animals have no knowledge of an escape platform. This finding suggests that drug and environment can fundamentally alter behavior in a way that facilitates more efficient spatial learning. Given the robust nature of passive avoidance learning, it was not surprising that all groups, regardless of treatment or rearing environment, exhibited recall latencies that did not differ significantly from the criterion time of $600 \mathrm{~s}$. Furthermore, neither treatment nor rearing environment altered recall of the avoidance task.

The relationship between enhanced basal hippocampal neuroplasticity and learning ability was further supported by the finding that these parameters were highly correlated. For each condition, the percent change in the basal NCAM PSA-positive cell number following the intervention (Table 2) was taken as an index of effect on neuroplasticity status while the mean latency to platform across all animals and all trials was taken as an index of spatial learning ability. Pearson analysis showed these measures of neuroplastic state and learning ability to be highly correlated 


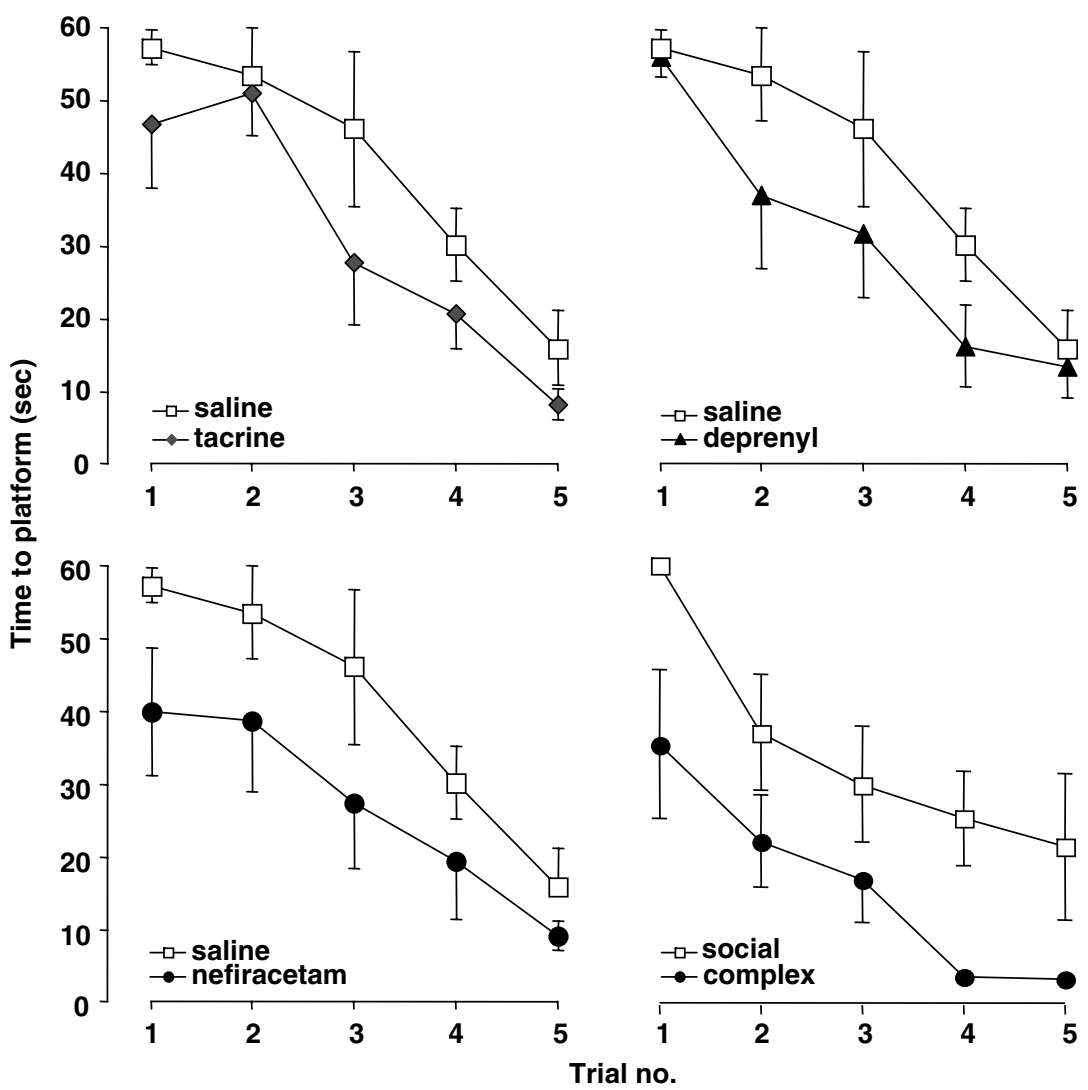

Figure 5 The consequence of chronic drug treatment and complex environment rearing on the spatial learning ability of rats. The figure shows the acquisition of water maze learning over five trials. Tacrine (I mg/kg/day), deprenyl $(5 \mathrm{mg} / \mathrm{kg} /$ day), nefiracetam (I5 mg/kg/day), and complex rearing significantly improved acquisition of platform location (saline vs nefiracetam, tacrine, and deprenyl-treated, two-way ANOVA: $F[1,40]=8.78, p=0.005$; $\mathrm{F}[\mathrm{I}, 40]=5.73, p=0.022$; and $\mathrm{F}[\mathrm{I}, 40]=5.78, p=0.026$, respectively; social vs complex environment, two-way ANOVA: $\mathrm{F}[\mathrm{I}, 40]=19.08, p<0.000 \mathrm{I})$. The data are the mean \pm SEM time to reach the platform in seconds $(n=5)$. NB: the last drug injection was administered $24 \mathrm{~h}$ prior to training to eliminate acute drug effects and animals reared in the complex environment were removed to social housing conditions $24 \mathrm{~h}$ prior to training.

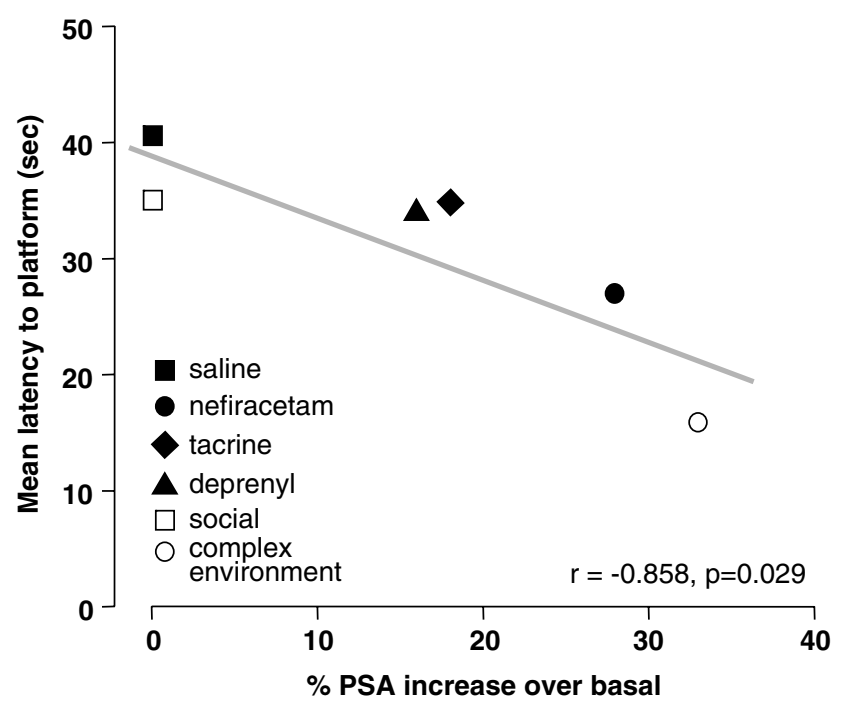

Figure 6 Relationship between hippocampal neuroplastic status and spatial learning ability. For each condition, the percent change in the basal NCAM PSA-positive cell number from the appropriate control group was taken from Table 2 as an index of effect on neuroplasticity status while the mean latency to platform across all animals and all trials was taken as an index of spatial learning ability. Pearson analysis showed these measures of neuroplastic state and learning ability to be highly correlated $(r=-0.858$, $p=0.029$ ).
(Figure 6; $r=-0.858, p=0.029$ ), indicating that the higher the basal NCAM PSA expression the better the learning ability of the animals.

\section{Chronic Drug Treatment or Complex Environment Rearing Mediates Resistance to the Amnesic Action of Scopolamine}

Here, the capacity of drug and environmental intervention to overcome a cholinergic deficit was investigated. In previous work we have shown that scopolamine administered $6 \mathrm{~h}$ following training induced robust amnesia for the passive avoidance task (Doyle and Regan, 1993). Here, both nefiracetam-treated and complex environment-reared groups showed a similar resilience to such scopolamineinduced amnesia of passive avoidance at the $24 \mathrm{~h}$ recall time (two-way ANOVA: $\mathrm{F}[1,38]=17.72, p=0.0002$ and $\mathrm{F}[1,21]=13.3, p=0.0015$, respectively) with an approximate 2.5 -fold increase in the dose of scopolamine required to achieve an equivalent deficit to that observed in the control animals (Figure 7).

\section{Combination of Drug and Environmental Interventions}

If both cognition-enhancing drugs and complex environment rearing enhance neural robustness by similar 


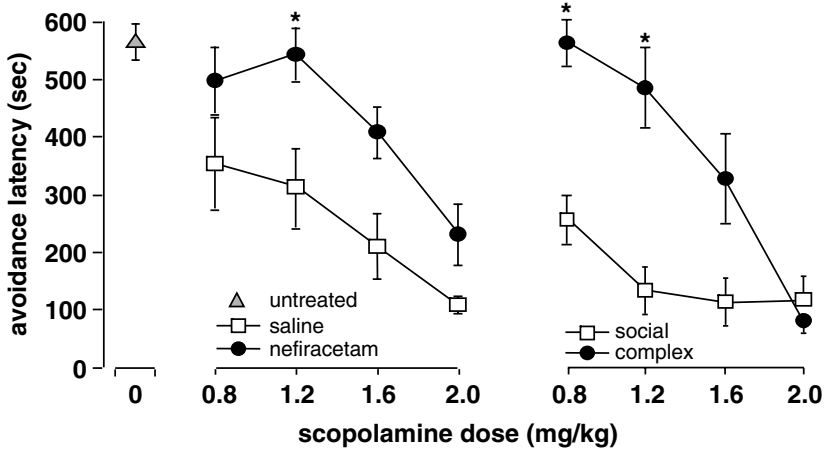

Figure 7 The consequence of chronic nefiracetam treatment and complex environment rearing on scopolamine-induced amnesia for the passive avoidance paradigm. The graphs show the resistance against scopolamine-induced amnesia (6h post-training; i.p.) conferred by nefiracetam $(15 \mathrm{mg} / \mathrm{kg} /$ day) and complex rearing (two-way ANOVA: $F[1,38]=17.72, p=0.0002$ and $F[1,21]=13.3, p=0.0015$, respectively). The data are the mean \pm SEM of the escape latencies $24 \mathrm{~h}$ post-training $(3 \leqslant n \leqslant 8)$. Values significantly different from the corresponding control are identified with an asterisk (Bonferroni post hoc test, $p<0.05$ ). NB: the last injection of nefiracetam was administered $24 \mathrm{~h}$ prior to training to eliminate direct effects of the nootropic and animals reared in the complex environment were removed to social housing conditions $24 \mathrm{~h}$ prior to training.

mechanisms then it may be expected that the system can be saturated. To address this, we examined the consequence of combining complex environment rearing and chronic treatment with a cognition-enhancing drug. While the enhancement of basal NCAM PSA-positive cell frequency following nefiracetam treatment alone was slightly less than that achieved by complex environment rearing, animals receiving both interventions exhibited no significant difference in dentate polysialylated cell frequency compared to either intervention alone (Figure 8).

Collectively, these data would tend to confirm the dominant effect of chronic drug treatment or complex environment rearing to be the development of a more robust neural structure.

\section{DISCUSSION}

Central to activity-related brain plasticity are enriched environments (Rosenweig et al, 1962). A great number of studies have demonstrated that environmental stimulation increases dendritic arborization and produces change at the level of the synapse in a manner that results in more robust cognitive function (Walsh et al, 1969; Greenough and Volkmar, 1973; Diamond et al, 1976; Moser et al, 1994; Nilsson et al, 1999). It is, therefore, not surprising that, in this study, complex environment rearing was found to enhance the frequency of polysialylated cells in the dentate infragranular zone and concomitantly improve spatial learning ability. Of particular interest, however, was the observation that chronic treatment with tacrine, nefiracetam, or deprenyl resulted in an increase in polysialylated cell frequency that was indistinguishable from that obtained with rearing in a complex environment.

Given that expression of polysialylated NCAM is a prerequisite for activity-dependent synaptic plasticity

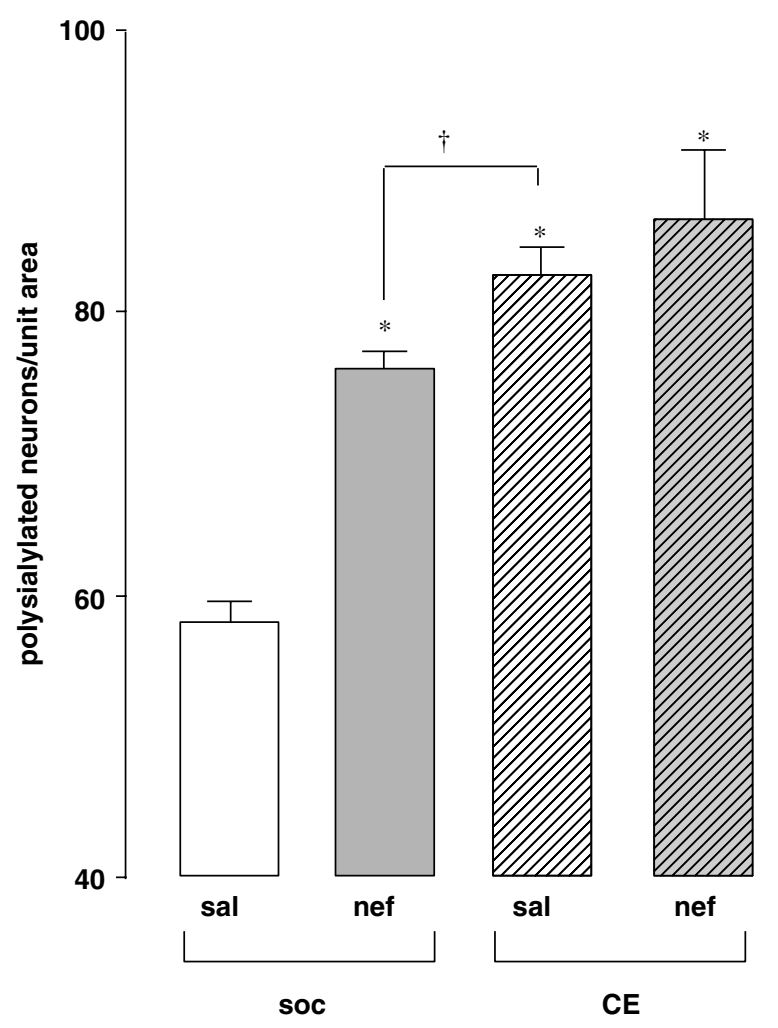

Figure 8 The influence of nefiracetam treatment and complex environment rearing alone and in combination on basal hippocampal NCAM PSA expression. Data represent mean \pm SEM number of cells/ $0.15 \mathrm{~mm}^{2}$ of the granule cell layer $(n=4)$. Significant difference from saline control and nefiracetam alone is indicated by an asterisk and cross, respectively (Student's $t$-test; $p<0.05)$. sal: saline $(0.9 \% \mathrm{w} / \mathrm{v})$; nef: nefiracetam ( $15 \mathrm{mg} / \mathrm{kg} /$ day); soc: social housing; CE: complex environment.

(Muller et al, 1996; Theodosis et al, 1999), it is perhaps not surprising that enhancing cholinergic function, long known to be necessary for memory consolidation (Doyle and Regan, 1993; Everitt and Robbins, 1997; Milner et al, 1998), modulates expression of this neuroplastic mechanism. Tacrine directly enhances acetylcholine transmission by inhibition of AChE while deprenyl will increase acetylcholine activity indirectly via improved dopamine function (Tariot et al, 1987; Piccinin et al, 1990; Mangoni et al, 1991; Molinengo and Ghi, 1997). Nefiracetam also exerts strong effects on cholinergic function and, in vitro, this nootrope has been shown to enhance neuritogenesis and NCAM PSA expression (Odumeru et al, 1997; Woodruff Pak and Hinchliffe, 1997; Oyaizu and Naharishi, 1999; Nishizaki et al, 2000; Narahashi et al, 2004). It is also likely that other transmitter systems enhancing neural activity will contribute to this neuroplastic response as previous studies have suggested activation of NMDA receptors to result in increased polysialylation in ex vivo preparations of neural tissue (Bouzioukh et al, 2001). However, drugs that dampen neural activity, such as NNC-711 and phenytoin, despite the cognition enhancing properties of the former, appear to have no effect on polysialylated cell frequency.

Thus, chronic treatment with a cholinergic activitypromoting, cognition enhancing drug or complex environment rearing increased the basal polysialylated cell 
frequency of the hippocampal dentate. However, the consequence of such enhanced basal plasticity for memory consolidation-associated activation of neuroplastic mechanisms remained unclear. To address this issue we evaluated the consequence of these protocols on the transient change in polysialylated cell frequency seen $12 \mathrm{~h}$ following training in either an avoidance conditioning or spatial learning paradigm. The magnitude of the polysialylation activation is significantly reduced following either drug- or environment-mediated enhancement of basal PSA expression. Of importance in this regard are recent studies that have compared the transient polysialylation response in individual rats and shown the response to be greater in animals exhibiting greatest difficulty in task acquisition (Sandi et al, 2004), suggesting the need for a more substantial NCAM PSA response in the consolidation of complex/difficult tasks. An alternative explanation for reduced learning induced activations would be the existence of a ceiling or maximal NCAM PSA expression level at postnatal day 80 . However, this is unlikely as, for example, water maze trained animals would then be expected to activate up to this 'ceiling', but these groups fail to exhibit any polysialylation increase at the $12 \mathrm{~h}$ time point following drug interventions.

Our observations are consistent with the idea that a chronic drug regimen or a complex environment induces a more robust memory pathway that can acquire and consolidate new information more efficiently. This hypothesis finds support in the improved learning behavior and enhanced resistance to cholinergic deficits seen following either intervention. Furthermore, the level of enhancement of basal neuroplastic status achieved by either drug or environmental intervention correlates directly with improved spatial learning ability. It is important to remember that improved learning and enhanced neuroplasticity result from alterations due to chronic exposure to these drugs and are not a consequence of acute drug action as drug treatment was ceased $24 \mathrm{~h}$ prior to training. Moreover, as a combination of both protocols failed to further increase basal polysialylated cell frequency, complex environment rearing and chronic drug regimens most likely attain a similar set point of PSA expression by the same mechanism(s).

As the frequency of the dentate polysialylated neurons declines markedly with age in both rodent and human populations (Fox et al, 1995; Abrous et al, 1997; Ní Dhúill et al, 1999), the effects of a chronic drug regimen or a complex environment may relate to an attenuation in the decline of this cell population. Indeed, polysialylated cell frequency declines earlier in animals reared in social groups as compared to a complex environment (unpublished observations). Such environmental or pharmacological intervention may prove highly relevant in certain disease states with well defined times of onset. For example, the expression of NCAM PSA is reduced in the hippocampal dentate of schizophrenic patients suggestive of a deficit in memory associated synaptic plasticity mechanisms (Barbeau et al, 1995). Thus, the benefits accruing from such procognitive interventions have the potential to oppose and even reverse aberrant synaptic connectivity patterning that likely underlie the developmental emergence of disorders such as autism, schizophrenia, and Alzheimer's disease
(Braak and Braak, 1991; Bobinski et al, 1995; Scheff et al, 1996; Feinberg, 1982; Hoffman and McGlashan, 1997; Mirnics et al, 2001; Volkmar and Pauls, 2003).

These studies suggest that improved memory-associated synaptic plasticity may be the fundamental mechanism underlying the disease modifying action of drugs such as AChEIs (Farlow et al, 2000). In support of this, in Alzheimer's disease, for example, there is a striking upregulation of NCAM polysialylation, but not NCAM polypeptide, in the dentate molecular layer (Gillian et al, 1994; Mikkonen et al, 1999). This most likely relates to repair associated with disappearance of degenerating axon terminals and reinnervation of the vacant postsynaptic sites with sprouted terminals of intact axons. This is consistent with the increased expression of NCAM PSA observed in the rat dentate molecular layer in response to the synaptic remodelling associated with lesion of the entorhinal inputs (Miller et al, 1994; Styren et al, 1994). Facilitation of synaptic reorganization, at least in part mediated by NCAM PSA, may represent an essential component of the purported disease-modifying actions of AChEIs. These studies suggest the molecular and cellular events underpinning neuroplastic responses to be novel targets for interventive drug strategies. Indeed, agents that more directly harness and enhance mechanisms of synaptic plasticity may be capable not only of symptomatic relief but reversal of fundamental deficits underpinning diseases such as Alzheimer's disease and schizophrenia.

\section{ACKNOWLEDGEMENTS}

This work was supported, in part, by Daiichi Pharmaceutical Co. Ltd, Tokyo, Japan and the Health Research Board of Ireland. The helpful contributions of Dr Tadashi Shiotani during the course of this work and Dr Helen Gallagher to an early draft manuscript are gratefully acknowledged. CMR and KJM are Science Foundation Ireland investigators.

\section{REFERENCES}

Abrous DN, Montaron MF, Petry KG, Rougon G, Darnaudery M, Le Moal $\mathrm{M}$ et al (1997). Decrease in highly polysialylated neuronal cell adhesion molecules and in spatial learning aduring ageing are not correlated. Brain Res 744: 285-292.

Alexinsky T, Przybyslawski J, Mileusnic R, Rose SPR, Sara J (1997). Antibody to day-old chick glycoprotein produces amnesia in adult rats. Neurobiol Learn Mem 67: 14-20.

Barbeau D, Liang JJ, Robitalille Y, Quirion R, Srivastava LK (1995). Decreased expression of the embryonic form of the neural cell adhesion molecule in schizophrenic brains. PNAS 92: 2785-2789.

Becker CG, Artola A, Gerardy-Schahn R, Becker T, Welzl H, Schachner M (1996). The polysialic acid modification of the neural cell adhesion molecule is involved in spatial learning and hippocampal long-term potentiation. J Neurosci Res 45: 143-152.

Blackard Jr WG, Sood GK, Crowe DR, Fallon MB (1998). Tacri. A cause of fatal hepatotoxicity? J Clin Gastroenterol 26: 57-59.

Bobinski M, Wegiel J, Wisniewski HM, Tarnawski M, Reisberg B, de Mlodzik B et al (1995). Atrophy of hippocampal formation subdivisions correlates with stage and duration of Alzheimer disease. Dementia 6: 205-210. 
Bouzioukh F, Tell F, Jean A, Rougon G (2001). NMDA receptor and nitric oxide synthase activation regulate polysialylated neural cell adhesion molecule expression in adult brainstem synapses. J Neurosci 21: 4721-4730.

Braak H, Braak E (1991). Neuropathological staging of Alzheimerrelated changes. Acta Neuropathol (Berl) 82: 239-259.

Burns A, Spiegel R, Quarg P (2004). Efficacy of rivastigmine in subjects with moderately severe Alzheimer's disease. Int $J$ Geriatr Psychiatry 19: 243-249.

Diamond MC, Ingham CC, Johnson RE, Bennett EL, Rosenweig MR (1976). Effects of environment on morphology of rat cerebral cortex and hippocampus. J Neurobiol 7: 75-85.

Dickson DW, Crystal HA, Bevona C, Honer W, Vincent I, Davies P (1995). Correlations of synaptic and pathological markers with cognition of the elderly. Neurobiol Aging 16: 285-298.

Doyle E, Regan CM (1993). Cholinergic and dopaminergic agents which inhibit a passive avoidance response attenuate paradigmspecific increases in NCAM sialylation state. J Neural Transm 92: 33-49.

Doyle E, Nolan P, Bell R, Regan CM (1992). Intraventricular infusions of anti-neural cell adhesion molecules in a discrete post-training period impair consolidation of a passive avoidance response in the rat. J Neurochem 59: 1570-1573.

Ebadi M, Sharma S, Shavali S, El Reaey H (2002). Neuroprotective actions of selegiline. J Neurosci Res 67: 285-289.

Everitt BJ, Robbins TW. (1997). Central cholinergic systems and cognition. Annu Rev Psychol 48: 649-684.

Farlow M, Anand R, Messina Jr J, Hartman R, Veach J (2000). A 52-week study of the efficacy of rivastigmine in patients with mild to moderately severe Alzheimer's disease. Eur Neurol 44: 236-241.

Feinberg I (1982). Schizophrenia: caused by a fault in programmed synaptic elimination during adolescence? J Psychiat Res 17: 319-334.

Foley AG, Hedigan K, Roullet P, Moricard Y, Murphy KJ, Sara SJ et al (2003). Consolidation of memory for odour-reward association requires transient polysialylation of the neural cell adhesion molecule in the rat hippocampal dentate gyrus. J Neurosci Res 74: 570-576.

Fox GB, O’Connell AW, Murphy KJ, Regan CM (1995). Memory consolidation induces a transient and time-dependent increase in the frequency of NCAM-polysialylated cells in the adult rat hippocampus. J Neurochem 65: 2796-2799.

Gillian AM, Brion JP, Breen KC (1994). Expression of the neural cell adhesion molecule (NCAM) in Alzheimer's disease. Neurodegeneration 3: 283-291.

Glatt SL, Hubble JP, Lyons K, Paolo A, Troster AI, Hassanein RE et al (1996). Risk factors for dementia in Parkinson's disease: effect of education. Neuroepidemiology 15: 20-25.

Gomez-Isla T, Price J, McKeel JL, Morris JC, Growdon JH, Hyman BT (1996). Profound loss of layer 2 entrohinal cortex neurons occurs in very mild Alzheimer's disease. J Neurosci 16: 4491-4500.

Greenough WT, Volkmar FR (1973). Pattern of dendritic branching in occipital cortex of rats reared in complex environments. Exp Neurol 40: 491-504.

Hoffman RE, McGlashan TH (1997). Synaptic elimination, neurodevelopment, and the mechanism of hallucinated 'voices' in schizophrenia. Am J Psychiat 154: 1683-1689.

Hoyk Z, Parducz A, Theodosis DT (2001). The highly sialylated isoform of the neural cell adhesion molecule is required for estradiol-induced morphological plasticity in the adult arcuate nucleus. Eur J Neurosci 13: 649-656.

Irizarry MC, Hyman BT (2001). Alzheimer disease therapeutics. J Neuropathol Exp Neurol 60: 923-928.

Kleene R, Schachner M (2004). Glycans and neural cell interactions. Nat Rev Neurosci 5: 195-208.
Krishnan KRR, Charles HC, Doraiswamy PM, Mintzer J, Weisler R, $\mathrm{Yu} \mathrm{X}$ et al (2003). Randomized, placebo-controlled trial of the effects of donepezil on neuronal merkers and hippocampal volumes in Alzheimer's disease. Am J Psychiat 160: 2003-2011.

Knapp M, Knopman D, Solomon P, Pendlebury W, Davis C, Gracon S (1994). A 30-week randomized controlled trial of highdose tacrine in patients with Alzheimer's disease. JAMA 271: 985-991.

Kuo CC, Bean BP (1994). Slow binding of phenytoin to inactivated sodium channels in rat hippocampal neurons. Mol Pharmacol 46: $716-725$.

Lamprecht R, LeDoux J (2004). Structural plasticity and memory. Nat Rev Neuroscience 5: 45-54.

Lüthi A, Laurent J-P, Figurov A, Muller D, Schachner M (1994). Hippocampal long-term potentiation and neural cell adhesion molecules L1 and NCAM. Nature 372: 777-779.

Mangoni A, Grassi MP, Frattola L, Piolti R, Bassi S, Motta A et al (1991). Effects of a MAO-B inhibitor in the treatment of Alzheimer disease. Eur Neurol 31: 100-107.

McNamara JO (2001). Drugs effective in the therapy of epilepsy. In: Hardman JG, Limbird LE (eds) Goodman and Gilman's The Pharmacological Basis of Therapeutics, 10th edn. McGraw-Hill: New York. pp 521-548 (ISBN 0-07-135469-7).

Mikkonen M, Soininen H, Tapiola T, Alafuzoff I, Miettinen R (1999). Hippocampal plasticity in Alzheimer's disease: changes in highly polysialylated NCAM immunoreactivity in the hippocampal formation. Eur J Neurosci 11: 1754-1764.

Miller PD, Styren SD, Lagenaur CF, DeKosky ST (1994). Embryonic neural cell adhesion molecule (N-CAM) is elevated in the denervated rat dentate gyrus. J Neurosci 14: 4217-4225.

Milner B, Squire LR, Kandel ER (1998). Cognitive neuroscience and the study of memory. Neuron 20: 445-468.

Mirnics K, Middleton FA, Lewis DA, Levitt P (2001). Analysis of complex brain disorders with gene expression microarrays: Schizophrenia as a disease of the synapse. TINS 24: 479-486.

Molinengo L, Ghi P (1997). Behavioral and neurochemical effects induced by subchronic l-deprenyl administration. Pharmacol Biochem Behav 58: 649-655.

Moser M-B, Trommald M, Andersen P (1994). An increase in dendritic spine density on hippocampal CA1 pyramidal cells following spatial learning in adult rats suggests the formation of new synapses. PNAS 91: 12673-12675.

Muller D, Wang C, Skibo G, Toni N, Cremer H, Calaora V et al (1996). PSA-NCAM is required for activity-induced synaptic plasticity. Neuron 17: 413-422.

Murphy KJ, O' Connell AW, Regan CM (1996). Repetitive and transient increases in hippocampal neural cell adhesion molecule polysialylation state following multi-trial spatial training. J Neurochem 67: 1268-1274.

Narahashi T, Moriguchi S, Zhao X, Marszalec W, Yeh JZ (2004). Mechanisms of action of cognitive enhancers on neuroreceptors. Biol Pharm Bull 27: 1701-1706.

Ní Dhúill CM, Fox GB, Pittock SJ, O’Connell AW, Murphy KJ, Regan CM (1999). Polysialylated neural cell adhesion molecule expression in the dentate gyrus of the human hippocampal formation from infancy to old age. J Neurosci Res 55: 99-106.

Nilsson M, Perfilieva E, Johansson U, Orwar O, Eriksson PS (1999). Enriched environment increases neurogenesis in the adult dentate gyrus and improves spatial memory. J Neurobiol 39: 569-578.

Nishizaki T, Nomura T, Matuoka T, Kondoh T, Enikolopo G, Sumikawa $\mathrm{K}$ et al (2000). The anti-dementia drug nefiracetam facilitates hippocampal synaptic transmission by functionally targeting presynaptic nicotinic ACh receptors. Brain Res $\mathrm{Mol}$ Brain Res 80: 53-62. 
Nothias F, Vernier P, von Boxberg Y, Mirman S, Vincent J-D (1997). Modulation of NCAM polysialylation is associated with morphofunctional modifications in the hypothalamoneurohypophysial system during lactation. Eur J Neurosci 9: 1553-1557.

O’Connell AW, Fox GB, Kjøller C, Gallagher HC, Murphy KJ, Kelly $J$ et al (2001). Anti-ischemic and cognition-enhancing properties of NNC-711, a $\gamma$-aminobutyric acid reuptake inhibitor. Eur $J$ Pharmacol 424: 37-44.

Odumeru O, Murphy KJ, O'Connell AW, Regan CM, Shiotani T (1997). Influence of nefiracetam on NGF-induced neuritogenesis and neural cell adhesion molecule polysialic acid expression: in vivo and in vitro comparisons. Behav Brain Res 83: 173-178.

Oyaizu M, Naharishi T (1999). Modulation of the neuronal nicotinic acetylcholine receptor-channel by the nootropic drug nefiracetam. Brain Res 822: 72-79.

Paxinos G, Watson C (1986). The Rat Brain in Stereotaxic Coordinates, 2nd edn. Academic Press: New York.

Piccinin GL, Finali G, Piccirilli M (1990). Neuropsychological effects of L-deprenyl in Alzheimer's type dementia. Clin Neuropharmacol 13: 147-163.

Raskind MA, Peskind ER, Wessel T, Yuan W (2000). Galanthamine in $\mathrm{AD}$ : A 6-month randomized, placebo-controlled trial with a 6-month extension. The Galanthamine-1 USA Study Group. Neurology 54: 2261-2268.

Regan CM (2004). Cell adhesion molecules. In: Riedel G, Blatt B (eds). Memories are Made of These: From Messengers to Molecules. Eurekah.com and Kluwer Academic/Plenum Publishers: Dordrecht/New York. pp 564-579 (ISBN 0-306-47862-5).

Rogawski MA, Porter RJ (1990). Antiepileptic drugs: pharmacological mechanisms and clinical efficacy with consideration of promising developmental stage compounds. Pharmacol Rev 42: 223-286.

Rogers S, Farlow M, Doody R, Mohs R, Friedhoff L (1998). A 24-week, double-blind, placebo-controlled trial in patients with Alzheimer's disease. Donepezil Study Group. Neurology 50: 136-145.

Rønn LC, Bock E, Linnemann D, Jahnsen H (1995). NCAMantibodies modulate induction of long-term potentiation in rat hippocampal CA1. Brain Res 677: 145-151.

Rosenweig MR, Krech D, Bennett EL, Diamond MC (1962). Effects of environmental complexity and training on brain chemistry and anatomy. J Comp Physiol Psychol 55: 45-56.

Rosler M, Anand R, Cicin-Sain A, Gauthier S, Agid Y, Dal-Bianco P et al (1999). Efficacy and safety of rivastigmine in patients with Alzheimer's disease: international randomised controlled trial. Br Med J 318: 633-638.

Rougon G, Dubois C, Buckley N, Magnani JL, Zollinger W (1986). A monoclonal antibody against meningococcus group $B$ polysaccharides distinguishes embryonic from adult NCAM. J Cell Biol 103: 2429-2437.
Sandi C, Cordero MI, Merino JJ, Kruyt ND, Regan CM, Murphy KJ (2004). Neurobiological correlates of individual differences in spatial learning ability. Learn Mem 11: 244-252.

Sandi C, Merino JJ, Cordero MI, Kruyt N, Murphy KJ, Regan CM (2003). Differential modulation of hippocampal NCAM polysialylation by stressful and traumatic experiences suggests distinct memory encoding mechanisms. Biol Psychiat 54: 599-607.

Scheff SW, Sparks DL, Price DA (1996). Quantitative assessment of synaptic density in the outer molecular layer of the hippocampal dentate gyrus in Alzheimer's disease. Dementia 4: 237-250.

Shorvon S (2001). Pyrrolidone derivatives. Lancet 358: 18851892.

Snowdon DA, Kemper SJ, Mortimer JA, Greiner LH, Wekstein DR, Markesbery WR (1996). Linguistic ability in early life and cognitive function and Alzheimer's disease in late life. Findings from the Nun Study. J Am Med Assoc 275: 528-532.

Standaert DG, Young AB (2001). Treatment of central nervous system disorders. In: Hardman JG, Limbird LE (eds) Goodman and Gilman's The Pharmacological Basis of Therapeutics 10th edn. McGraw-Hill: New York. pp 549-568 (ISBN 0-07-135469-7).

Styren SD, Lagenaur CF, Miller PD, DeKosky ST (1994). Rapid expression and transport of embryonic N-CAM in dentate gyrus following entorhinal cortex lesion: ultrastructural analysis. J Comp Neurol 349: 486-492.

Tariot PN, Cohen RM, Sunderland T, Newhouse PA, Yount D, Mellow AM et al (1987). L-deprenyl in Alzheimer's disease. Arch Gen Psychiatr 44: 427-433.

Terry RD, Masliah E, Salmon DP, Butters N, DeTeresa R, Hill R et al (1991). Physical basis of cognitive alterations in Alzheimer's disease: synapse loss is the major correlate of cognitive impairment. Ann Neurol 30: 572-580.

Theodosis DT, Bonhomme R, Vitiello S, Rougon G, Poulain DA (1999). Cell surface expression of polysialic acid on NCAM is a prerequisite for activity-dependent morphological neuronal and glial plasticity. J Neurosci 19: 10228-10236.

Volkmar FR, Pauls D (2003). Autism. Lancet 362: 1133-1141.

Walsh RN, Budtz-Olsen OE, Penny JE, Cummins RA (1969). The effects of environmental complexity on the histology of the rat hippocampus. J Comp Neurol 137: 361-366.

Wang S, Scott BW, Wojtowicz JM (2000). Heterogenous properties of dentate granule neurons in the adult rat. J Neurobiol 42: 248-257.

Woodruff Pak DS, Hinchliffe RM (1997). Mecamylamine- or scopolamine-induced learning impairment: ameliorated by nefiracetam. Psychopharmacology (Berl) 131: 130-139.

Young D, Lawlor PA, Leone P, Dragunow M, During MJ (1999). Environmental enrichment inhibits spontaneous apoptosis, prevents seizures and is neuroprotective. Nat Med 5: $448-453$. 